\title{
Dinâmica Eletrônica em Nanomateriais: Interações Multi-Eletrônicas em Pontos Quânticos
}

\section{Henrique B Nunciaroni, Gabriel Nagamine e Lázaro A. Junior.}

\section{Resumo}

Este trabalho consiste em analisar a dinâmica de multi-éxiton em nanomateriais semicondutores do tipo CulnS 2 . Para isso, usamos técnicas experimentais composto por um laser pulsado com resolução de 100 femtossegundos. Ao identificar a presença de multi-éxciton, como biéxciton e trions, o problema foi explorado empregando a estatística de Poisson que descreve perfeitamente a evolução da população de espécies excitadas em nanomateriais.

\section{Palavras-chave:}

Espectroscopia ultra-rápida; quantum dots

\section{Introdução}

Espectroscopia ultrarrápida, nada mais é que o estudo das propriedades ópticas e eletrônicas dos materiais utilizando sistemas compostos por lasers de pulsos ultracurtos.

Em especial, neste trabalho, demos ênfase no experimento de absorção transiente, com o objetivo de conseguir observar a intensidade das interações multiéxcitons em amostras de mesma composição e dimensões variadas. Na configuração do experimento usamos um pulso de bombeio com fótons de $3.1 \mathrm{eV}$ variando sua intensidade em pelo menos uma ordem de grandeza. Já para o pulso de prova, fixamos a energia próximo ao primeiro pito de absorção linear de cada amostra estudada.

\section{Resultados e Discussão}

Da figura 1(a) podemos ver que a intensidade da componente que decai com um tempo rápido aumenta de acordo com a potência do pulso de bombeio. Caso o gráfico apresentado em 1(a) respeite a estatística de Poisson, temos que, o aumento da intensidade do tempo rápido é devido a presença de multi-éxciton decaindo por efeito Auger. As amplitudes para os ajustes com a estatística de Poisson são extraídas da figura $1(\mathrm{~b})$, onde temos que " $B$ " representa a contribuição de pelo menos um éxciton, "A' " pelo menos dois éxcitons e $A=A^{\prime}+B$ intensidade inicial.
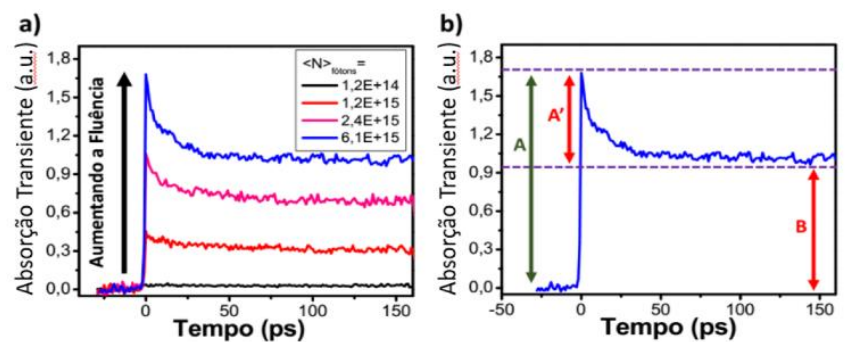

Figura 1: Em (a) são os dados adquiridos do experimento de absorção do transiente. Já em (b), temos uma representação para alguns valores das expressões de Poisson.

A expressão que modela a dinâmica de multi-éxcitons é dada por:

$B=-2-e^{<N>a b s} *\left(2+<N>_{a b s}\right)$

$A=1-e^{<N>a b s}$

onde $\langle N\rangle_{a b s}$ é a média de fótons absorvidos. A figura 2 apresenta os dados coletados para três amostras de tamanho distintos, e o modelo estatístico de Poisson aplicado nos dados.
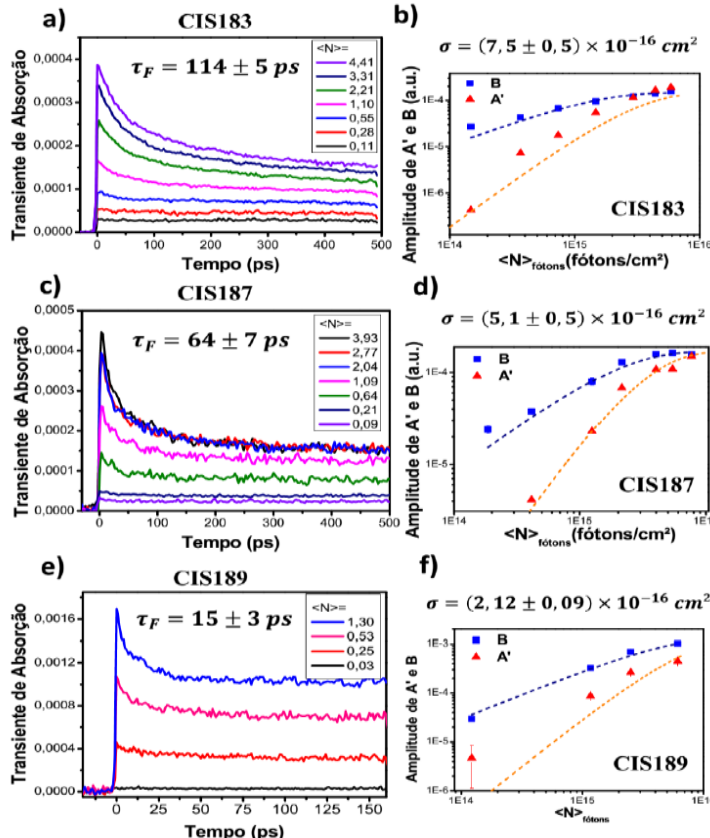

d)

$\sigma=(5,1+0,5) \times 10^{-16} \mathrm{~cm}^{2}$
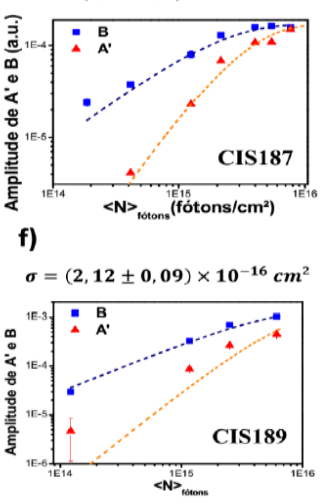

Figura 2: Em (a), (c) e (e) temos os dados extraído através do experimento absorção e transiente, onde $\boldsymbol{\tau}_{\mathbf{f}}$ é o decaimento rápido. Para (b), (d) e (f) apresentamos as retas teórica para a estatística juntamente com os pontos dos dados coletados, $\boldsymbol{\sigma}$ representa a seção de choque.

\section{Conclusão}

Da figura 3, temos o comparativo entre o tempo de vida do efeito Auger com relação a fotoluminescência.
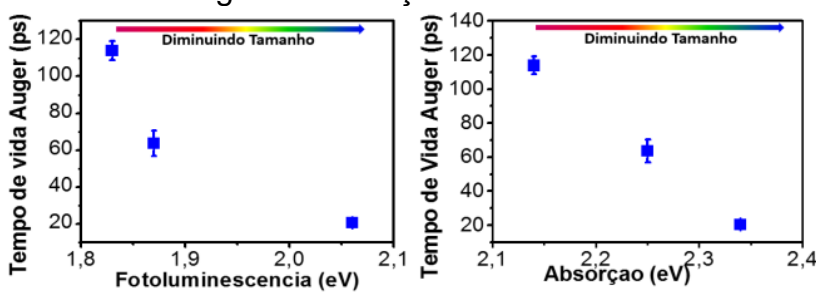

Figura 3: Gráfico do tempo de Auger pela fotoluminescência.

Disso, podemos concluir que quanto menor a amostra maior é sua interação entre os portadores de cargas excitados, que faz todo sentido físico uma vez que os elétrons então mais próximos um dos outros.

\section{Agradecimentos}

Agradeço a tudo grupo USL em especial Gabriel Nagamine e Prof.Dr Lázaro A. Padilha. 